\title{
VANCOMYCIN USE IN CHILDREN: IS THE RECOMMENDED DOSING TOO LOW?
}

\author{
Kristín Óskarsdóttir ${ }^{1}$, Pétur Gunnarsson², Sólveig Hafsteinsdóttir ${ }^{3}$, Hrólfur Brynjarsson ${ }^{3}$ Ásgeir Haraldsson ${ }^{1,3}$, Valtýr Stefánsson Thors ${ }^{1,3}$ \\ ${ }^{1}$ Faculty of Medicine, University of Iceland, ${ }^{2}$ Department of Hospital Pharmacy, Landspitali University Hospital Iceland, \\ ${ }^{3}$ Children's Hospital, Landspitali University Hospital, Iceland
}

Introduction: Vancomycin is a frequently used antibiotic in paediatric inpatient care. Recent data suggests that target trough levels should be $10-20 \mathrm{mg} / \mathrm{L}$ to achieve bacterial killing of MRSA, enterococci and coagulase negative staphylococci. The recommended paediatric dose $(40-50 \mathrm{mg} / \mathrm{kg} / \mathrm{day})$ is often insufficient to reach these levels leading to significant delays in reaching target trough levels with potential increase in morbidity/mortality. The aim of this study was to evaluate if current dosing regimens were sufficient to reach therapeutic levels and if therapeutic drug monitoring (TDM) led to altered dosing vancomycin at the Children's Hospital Iceland from 20122016.

Material and methods: This was a retrospective study investigating all children (younger than 18 years) who received $\geq 1$ intravenous dose of vancomycin at the Children's Hospital Iceland, during the study period, 2012-2016, using electronic medical records. Student t-test and dichotomous regression analysis were used for statistical analysis.

Results: 105 children received 163 vancomycin treatments, of which a third were in neonates (<30 days). Average daily starting dose in neonates was $24.8 \mathrm{mg} / \mathrm{kg} / \mathrm{day}$ and $39.7 \mathrm{mg} / \mathrm{kg} /$ day for others. TDM was never done in 58 treatments $(35.6 \%)$ of which in 12 only one dose was given. When assessing first trough levels, about $2 / 3$ were $<10 \mathrm{mg} / \mathrm{L}$ and in around $92 \%$ of cases $<15 \mathrm{mg} / \mathrm{L}$ (Fig. 1).

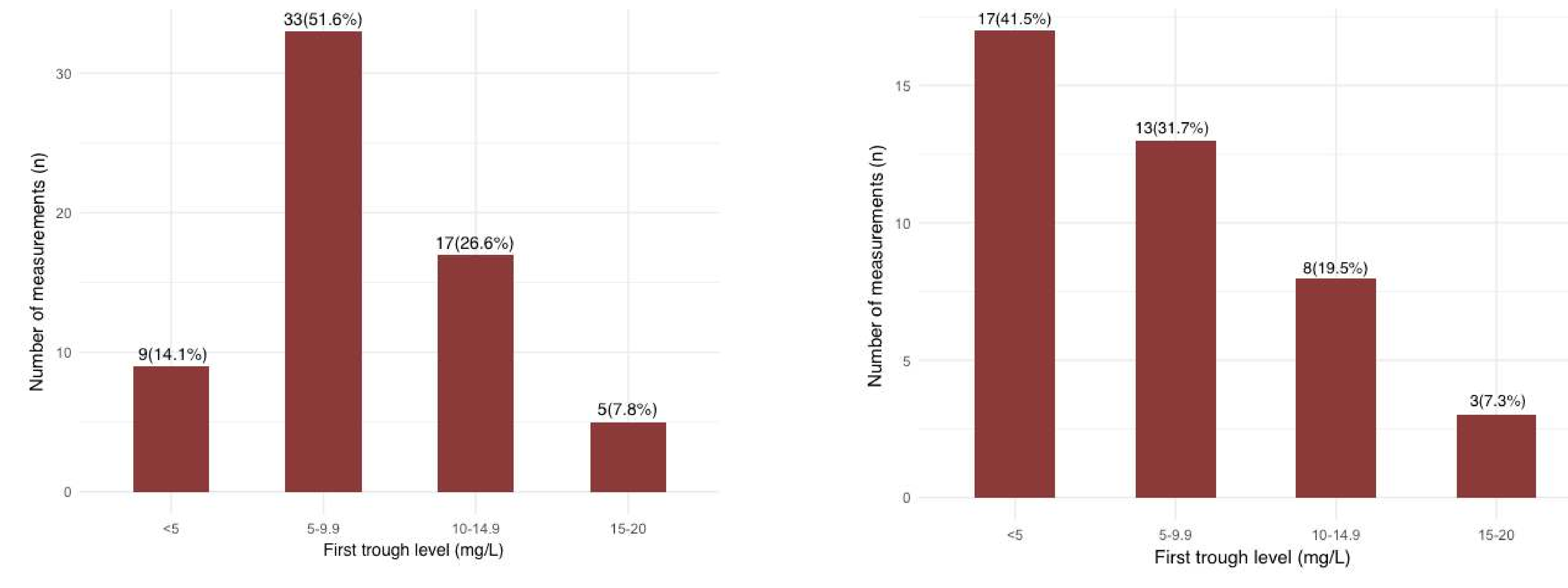

Figure 1: First trough levels in neonates (<30 days old) (A) and children older than 30 days (B).
Results: Of 275 total TDM levels done, 144 (52.4\%) were <10mg/L (Fig. 2) but only led to an increase in dose in $38(26.4 \%)$ cases. All age categories showed similar rates of favourable TDM, most of them well below 50\% (Fig. 3). A starting dose above $45 \mathrm{mg} / \mathrm{kg} /$ day was associated with better chance of therapeutic $(10-20 \mathrm{mg} / \mathrm{L}) \mathrm{drug}$ levels when compared with other dosing $(p=0.027)$. Malignancy was associated with increased risk of subtherapeutic levels compared with all other children where only $11.8 \%$ had therapeutic levels compared to $34.9 \%$ in other groups $(p=0.086)$.

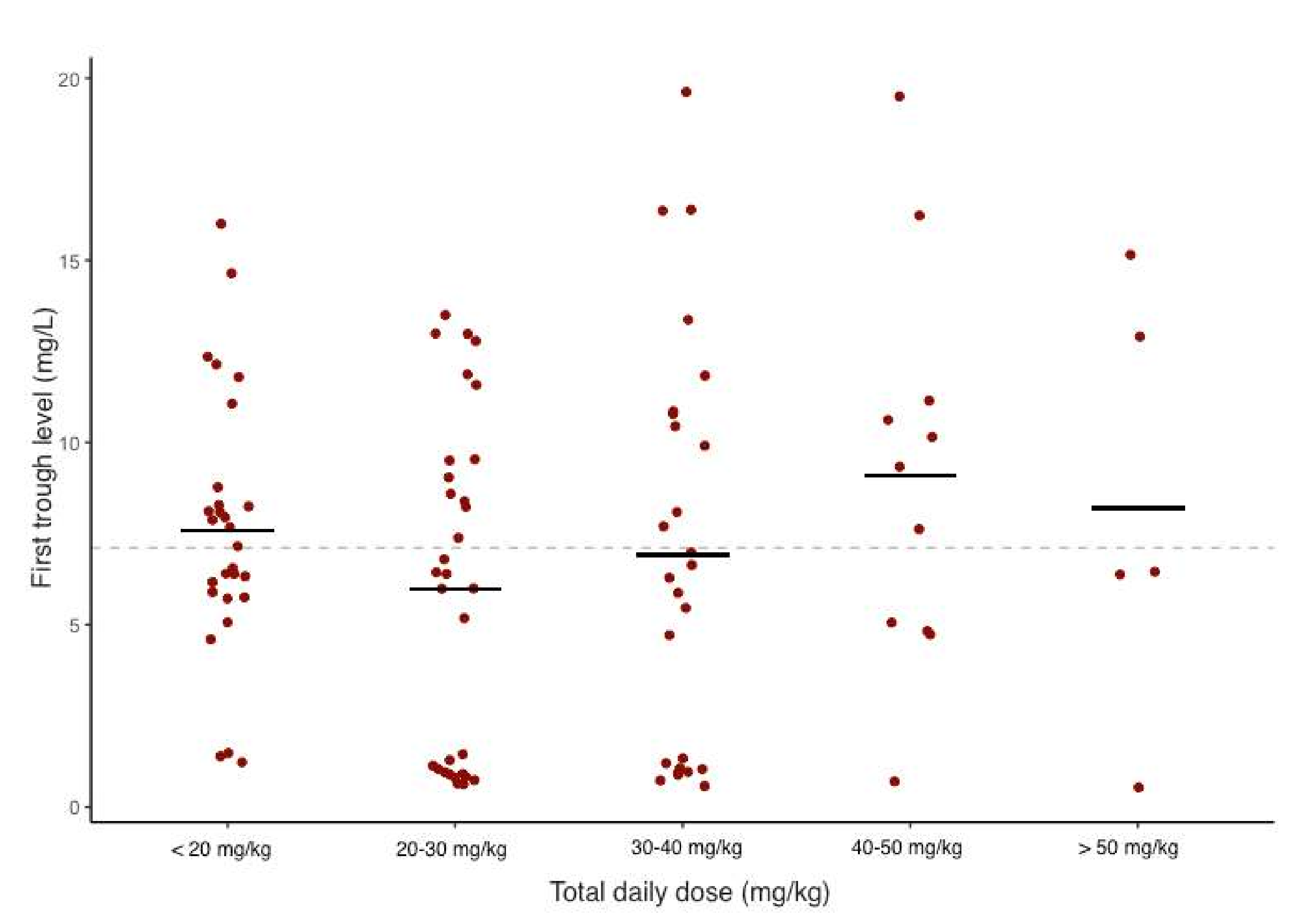

Figure 2: Daily doses of vancomycin and trough levels. Dotted line: Total average. Solid black lines: Average levels within group.

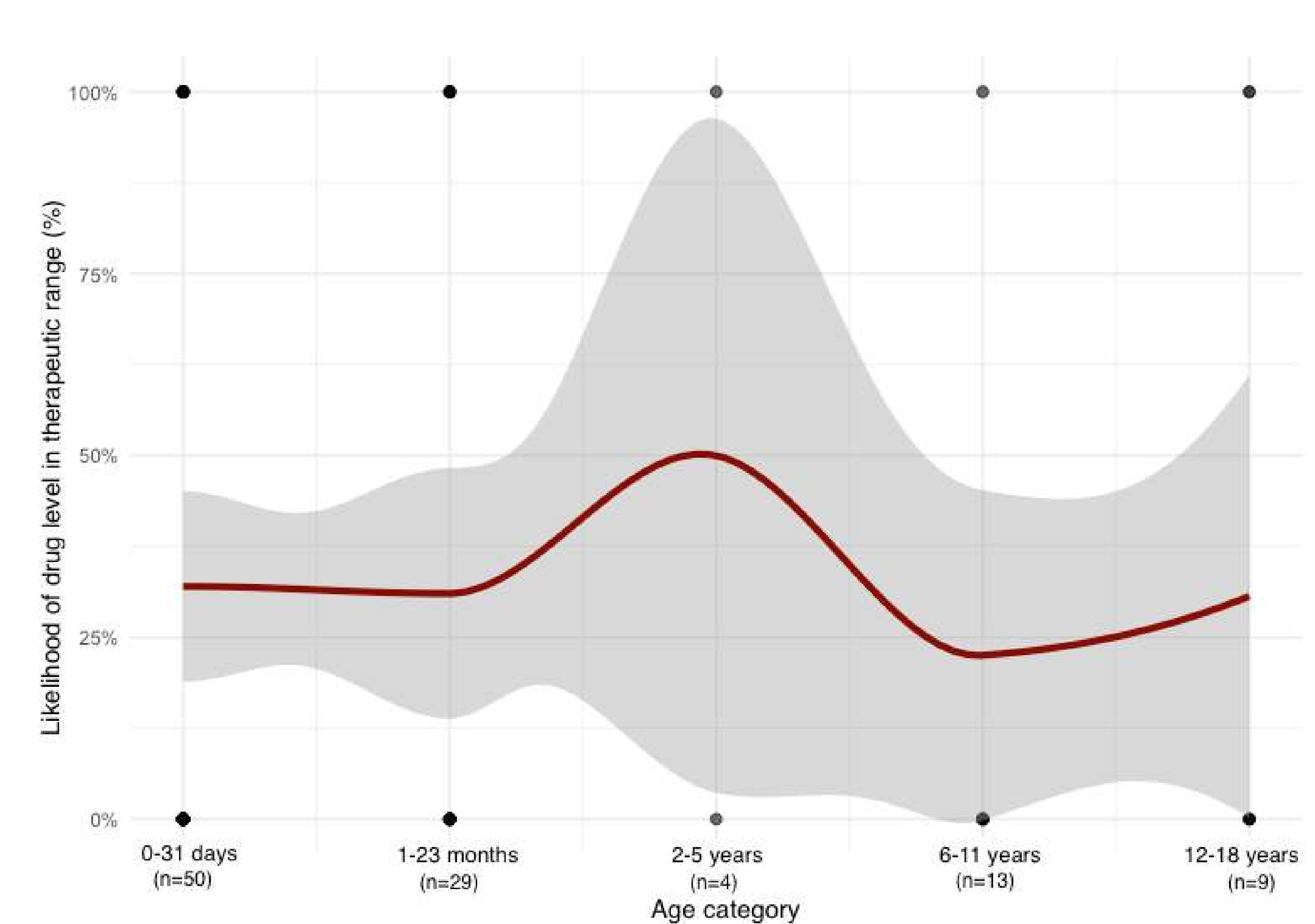

Figure 3: Likelyhood of therapeutic drug levels by age range. Red line: mean \% of therapeutic levels with $95 \% \mathrm{Cl}$ (gray area).
Discussion: In a large proportion of started vancomycin treatments, no TDM was done. In more than half of the cases, drug levels were $<10 \mathrm{mg} / \mathrm{L}$ and malignancy was associated with lower trough levels with only $11.8 \%$ having therapeutic levels. A subtherapeutic level only led to increase in daily dose in 38/144 (26.4\%) of cases, potentially delaying bactericidal effects of the antibiotic. This study suggests that starting doses of vancomycin in children should be reconsidered, especially in relation to malignant diseases and supports the importance of antibiotic stewardship to ensure optimal antibiotic use.

Correspondence: valtyr@lsh.is 